\title{
ENVIRO-LEGAL FACETS OF ADAPTIVE STRATEGIES AND MITIGATION MEASURES TO COMBAT CLIMATE CHANGE
}

\section{Dr. Shivalkumar} M.A *

\section{INTRODUCTION}

The climate change is a change in the statistical distribution of weather patterns and their changes over millions of years. It may be referred to a change in average weather conditions or change in the time variation of weather around long-term average conditions. It is caused naturally by some geological process augmented by the human beings through their activities causing the process of global warming to hasten and thereby creating alarming situation globally.

The earth is surrounded by a layer of gases that keep its surface warm and is able to sustain life. Since industrial revolution, this layer has grown thicker, as human beings produce more and more greenhouse gases trapping its heat. While greenhouse gases occurs naturally, they are also produced by burning of fossil fuels and through other human activities like development projects, industries vehicular traffic etc., as a result, our planet is getting warmer faster than ever before; and this process is known as global warming, which over a period of time brought lot of changes in the climate and is known as climate change.

The Inter-governmental Panel of Climate Change (IPCC) defines climate change as a change in the state of the climate that can be identified by changes in the mean and or the variability of its properties and that persists for an extended period, typically decades or longer. Climate changes may be due to natural internal processes or external forces, or to persistent anthropogenic changes in the composition of the atmosphere or in land use.

United Nations Framework Convention on Climate Change (UNFCC) defines 'Climate Change' as a change of climate which is attributed directly or indirectly to human activity that alerts the composition of the global atmosphere and which is in addition to natural climate variability observed over comparable time periods.

Climate change refers to the noticeable atmosphere changes like rising temperature that have been obvious from the middle of the $20^{\text {th }}$ century and have been occurring as a result of increased levels of greenhouse gases released by burning of fossil fuels. The climate change is the long-term shift in weather patterns in a specific region or globally. It refers to changes in a regions overall weather patterns, including rainfall, temperature, cloud cover etc.,

\section{Greenhouses Gases (GHGs)}

Greenhouses gases occur naturally, but they are also produced through human activity, such as burning of fossil fuels. These gases have an effect similar to the glass roof of a greenhouse. They not only allow the sun rays to penetrate the atmosphere so as the heat up the each, but also prevent part of the energy from being radiated back into the space. Greenhouse gases (GHGs) are the gases that have a potential for global warming. They have the capacity to absorb and give out infrared radiation. They create a radioactive forcing when they reflect the heat back to the atmosphere. Their mean warming temperature is $33^{\circ} \mathrm{C}$.

Water vapour, Co2, methane, nitrous oxide, ozone, chlorofluo rocarbons (CFCs), hydro-chlorofluorocarbons (HCFCs) and perfluorocarbons are the primary greenhouses gases. It is to www.worldwidejournals.com be noted that the amount of the water vapour in the atmosphere is not changes by the activities of the human beings. Greenhouses gases have been increasing ever since the Industrial Revolution in $1750{ }^{2}$

\section{Green House Effect}

The greenhouse effect is a naturally occurring phenomenon that blankets the earth lower atmosphere and warms it. Maintaining the temperature suitable for living things to survive. Just as greenhouses, that keeps the air warm inside its chamber, water vapor and greenhouse gases warms the Earth. Greenhouse gases play an important role in the balance of Earth's cooling and warming. According to one estimate, in the absence of naturally occurring greenhouse effect, the average temperature of the earth surface would by $19^{\circ} \mathrm{C}$ instead of present value of $15^{\circ} \mathrm{C}$ and the earth would be a frozen lifeless planet.

4. Global Warming Potential and Atmospheric Lifetime for Major Greenhouse Gases

\begin{tabular}{|l|l|l|l|l|}
\hline SL & $\begin{array}{l}\text { Greenhouse } \\
\text { Gases }\end{array}$ & $\begin{array}{l}\text { Chemical } \\
\text { Formula }\end{array}$ & $\begin{array}{l}\text { Global } \\
\text { Warming } \\
\text { Potential. 100 } \\
\text { year time } \\
\text { horizon }\end{array}$ & $\begin{array}{l}\text { Atmosphe } \\
\text { ric } \\
\text { Lifetime } \\
\text { (years) }\end{array}$ \\
\hline 1 & Carbon Dioxide & Co2 & 1 & $100^{+}$ \\
\hline 2 & Methane & CH4 & 25 & 12 \\
\hline 3 & Nitrous Oxide & N20 & 265 & 121 \\
\hline 4 & $\begin{array}{l}\text { Chloroflurocarb } \\
\text { on-12 }\end{array}$ & CFC12 & 10,200 & 100 \\
\hline 5 & $\begin{array}{l}\text { Hydro } \\
\text { fluorocarbon }\end{array}$ & HFC & 12,400 & 222 \\
\hline 6 & $\begin{array}{l}\text { Sulfur } \\
\text { Hexafluoride }\end{array}$ & SF6 & 23,500 & 3,200 \\
\hline 7 & $\begin{array}{l}\text { Nitrogen } \\
\text { Trifluoride }\end{array}$ & NF6 & 16,100 & 500 \\
\hline
\end{tabular}

The table below shows the relative concentrations of these major greenhouse gases and their sources. Some gases (like CO2) are made by both natural and manmade processes, while others (like hydrofluorocarbons) are only the result of human industrial activity. CO2 is typically measured in parts per million because it is 1,000 times more prevalent than the other gases, but is shown as parts per billion in the table for consistency ${ }^{3}$

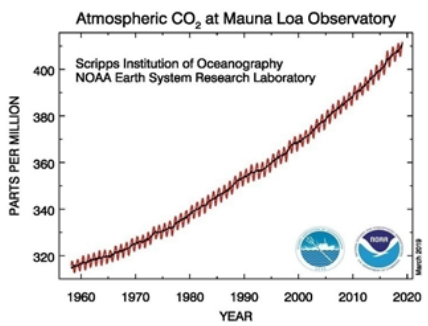

This figure shows the monthly mean carbon dioxide measurement at the Mauna Loa Observatory in Hawaii since 1958. The red line shows the monthly mean while the black shows the same after correcting for the average seasonal cycle. The small up and down saw-tooth pattern reflects seasonal changes in the release and uptake of carbon dioxide by plants. ${ }^{4}$ 
This indicator measures the "radiative forcing" or heating effect caused by greenhouse gases in the atmosphere. Radiative Forcing Caused by Major Long-Lived Greenhouse Gases, 1979-2019.

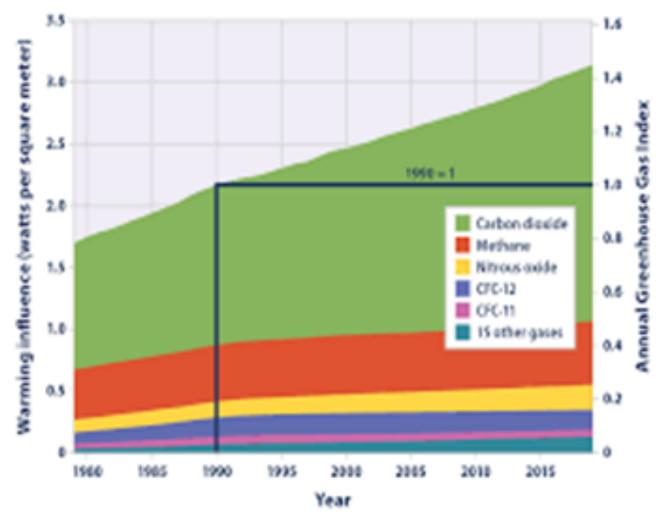

The above figure shows the amount of radioactive forcing caused by various greenhouse gases, based on the change in concentration of these gases in the Earth's atmosphere since 1750. Radioactive forcing is calculated in watts per square meter, which represents the size of the energy imbalance in the atmosphere. On the right side of the graph, radioactive forcing has been converted to the Annual Greenhouse Gas Index, which is set to a value of 1.0 for 1990.

\section{Current Actions for Adaptation and Mitigation}

Adaption, in the context of climate change, comprises the measures taken to minimize the adverse impacts of climate change, e.g. relocating the communities living close to the sea shore, for instance, to cope with the rising sea level or switching to crops that can withstand higher temperatures. Mitigation comprises measures to reduce the emissions of greenhouse gases that cause climate change in the first place, e.g. by switching to renewable sources of energy such as solar energy or wind energy or nuclear energy instead of burning fossil fuel in thermal power stations. Current Indian government expenditure on adaption to climate variability, exceeds $2.6 \%$ of the GDP, with agriculture, water resources, health and sanitation, forests, coastal-zone infrastructure and extreme weather events, being specific areas of concern.

\section{India's National Action Plan on Climate Change}

In dealing with the challenge of climate change we must act on several fronts in a focused manner simultaneously. The National Action Plan hinges on the development and use of new technologies. The implementation of the plan would be through appropriate institutional mechanisms suited for effective delivery of each individual Mission's objectives and include public private partnerships and civil society action. The focus will be on promoting understating of climate change, adaptation and mitigation, energy efficiency and natural resources conservation There are eight national missions and polices and programme which form the core of the National Action Plan, representing multipronged, longterm and integrated strategies for achieving key goals in the context of climate change.

\section{(I) National Solar Mission;}

(ii) The National Mission for Enhanced Energy Efficiency;

(iii) NationalWater Mission;

(iv) National Mission for Sustaining the Himalayan Ecosystem;

(v) National Mission for a Green India;

(vi) National Mission for Sustainable Agriculture ;

(vii)The National Mission on Strategic Knowledge for Climate Change;

(viii)National Bio-Energy Mission;

(ix) INDC in Paris Agreement (India's Intended Nationally Determined Contributions);

(x) Indian Network on Climate Change Assessment;

(xi) National Communication (NATCOM);
(xii)Introduction of labeling programme for appliance;

(xiii)Energy Conservation Building Code;

(xiv) Green Rating for Integrated Habitat Assessment;

(xv)Energy audits for large industrial consumers;

(xvi)Mass transport;

(xvii)Clean Air Initiatives;

(xviii)Promotion of energy saving devices;

(xix)Indian solar loan programme;

(xx)National initiative on climate resilient agriculture (NICRA);

(xxi)Fame India Programme; and

(xxii)The National Adaption Fund for Climate Change.

\section{International Initiatives on Climate Change} (I) United National Framework Convention on Climate Change

The United Nations Framework Convention on Climate Change (UNFCCC) established an international environmental treaty to combat "dangerous human interference with the climate system", in part by stabilizing greenhouse gas concentrations in the atmosphere. It was signed by 154 states at the United Nations Conference on Environment and Development (UNCED), informally known as the Earth Summit, held in Rio de Janeiro from 3 to 14 June 1992.Any Government, Government bodies, private parties or persons who are interested is saving the planet can attend and participate in the negotiations or international meets. They are known as CoPs or Conference on Parties, so far, 26 CoP were organized. The first CoP was organized in Berlin in 1995 and the 26th CoP was held in SEC center in Glasgow, Scotland United Kingdom between 31st October 13th November 2021. It was the first time since COP2 1 that parties were expected to commit to enhanced ambition towards mitigating climate change. As outlined in the Paris Agreement, parties are required to carry out a process colloquially known as the 'ratchet mechanism' every five years to give new national pledges.

UNFCC Climate Dialogues 2020 provided a platform for Parties and other stakeholders to showcase progress in 2020 and exchange views and ideas to pave the way for a successful glasgow conference with a total of 83 meetings, the Climate Dialogues was one of the largest virtual events on the United Nations agenda in 2020. Over 8,000 registered participants attended the meetings and interacted with the presenters and other participants at the virtual venue. The twelfth meeting of the research dialogue explored scientific research and understanding of ways to move towards net zero carbon dioxide emissions and build resilience to the impacts and risks of climate change in this context, During the Climate Dialogues 2020, an event on The Importance of Compliance: lessons learned and best practices as input into the effective functioning of the Paris Agreement Implementation and Compliance Committee was convened to bring together representatives from Parties as well as chairs of different compliance committees to share their experiences and promote implementation and compliance with the Paris Agreement. This event helped foster a deeper level of engagement, knowledge-building and information exchange among the implementation and compliance committees of various multilateral environmental agreements to assist the Paris Agreement Implementation and Compliance Committee in further developing its rules of procedure. The Doha Amendment, which established the second commitment period under the Kyoto Protocol in 2012, entered into force on 31 December 2020. The Doha Amendment strengthens the emission limitations or reduction commitments of developed countries, including countries with economies in transition, and sets an overall goal of reducing greenhouse gas emissions by 18 per cent compared with the 1990 level in 2013-2020. The Doha amendment's entry into force is a strong signal of a unified, multilateral commitment to address climate change.

The Kyoto Protocol, which was signed in 1997 and ran from 
2005 to 2020 , was the first implementation of measures under the UNFCCC.The Kyoto Protocol was superseded by the Paris Agreement, which entered into force in 2016. By 2020 the UNFCCC had 197 states parties. Its supreme decision-making body, the Conference of the Parties (COP), meets annually to assess progress in dealing with climate change. The treaty established different responsibilities for three categories of signatory states. These categories are developed countries, developed countries with special financial responsibilities, and developing countries.

The Kyoto Protocol is based on the principles and provisions of the Convention and follows its annex-based structure. It only binds developed countries, and places a heavier burden on them under the principle of "common but differentiated responsibility and respective capabilities", because it recognizes that they are largely responsible for the current high levels of GHG emissions in the atmosphere In its Annex B, the Kyoto Protocol sets binding emission reduction targets for 37 industrialized countries and economies in transition and the European Union. Overall, these targets add up to an average 5 per cent emission reduction compared to 1990 levels over the five year period 2008-2012 (the first commitment period) In Doha, Qatar, on 8 December 2012, the Doha Amendment to the Kyoto Protocol was adopted for a second commitment period, starting in 2013 and lasting until 2020.

The Kyoto Protocol allows Annex I Parties to add to or subtract from their initial assigned amount, thus raising or lowering the level of their allowed emissions over the commitment period, by trading Kyoto units with other Parties.

These additions and subtractions are carried out in accordance with the so-called Kyoto mechanisms;

(a) Emissions trading under Article 17;

(b) Joint implementation (JI) under Article 6; and

(c) Clean development mechanism (CDM) under Article 12.

These Kyoto mechanisms enhance the flexibility of Annex I Parties to meet their emission reduction or limitation commitments, by allowing these Parties to take advantage of lower-cost emission reductions outside their territories. This manual does not consider activities under the mechanisms but instead focuses on changes in the level of assigned amount for Annex I Parties arising from their use, A Party's eligibility to participate in each of the Kyoto mechanisms is determined as a normal outcome of the reporting, review and compliance procedures under the Kyoto Protocol. ${ }^{9}$

\section{Paris Agreement on Climate Change}

The Paris Agreement is a legally binding international treaty on climate change. It was adopted by 196 Parties at COP 21 in Paris, on 12 December 2015 and entered into force on 4 November 2016. Its goal is to limit global warming to well below 2, preferably to 1.5 degrees Celsius, compared to pre-industrial levels. To achieve this long-term temperature goal, countries aim to reach global peaking of greenhouse gas emissions as soon as possible to achieve a climate neutral world by mid-century. The Paris Agreement is a landmark in the multilateral climate change process because, for the first time, a binding agreement brings all nations into a common cause to undertake ambitious efforts to combat climate change and adapt to its effects, Implementation of the Paris Agreement requires economic and social transformation, based on the best available science. The Paris Agreement works on a 5- year cycle of increasingly ambitious climate action carried out by countries. By 2020, countries submit their plans for climate action known as nationally determined contributions (NDCs). In their NDCs, countries communicate actions they will take to reduce their Greenhouse Gas emissions in order to reach the goals of the Paris Agreement. Countries also communicate in the NDCs actions they will take to build resilience to adapt to the impacts of rising temperatures, With the Paris Agreement; countries established an enhanced transparency framework (ETF). Under ETF, starting in 2024, countries will report transparently on actions taken and progress in climate change mitigation, adaptation measures and support provided or received. It also provides for international procedures for the review of the submitted reports.

\section{The Montreal Protocol on Substances that Deplete the Ozone Layer}

The Montreal Protocol on Substances that Deplete the Ozone Layer is the landmark multilateral environmental agreement that regulates the production and consumption of nearly 100 man-made chemicals referred to as ozone depleting substances (ODS). When released to the atmosphere, those chemicals damage the stratospheric ozone layer, Earth's protective shield that protects humans and the environment from harmful levels of ultraviolet radiation from the sun. The Protocol includes provisions related to Control Measures Calculation of control levels, Control of trade with non-Parties, Special situation of developing countries, Reporting of data, Non-compliance, Technical assistance, as well as other topics. The substances controlled by the treaty are listed in Annexes A (CFCs, halons), B (other fully halogenated CFCs, carbon tetrachloride, methyl chloroform), C (HCFCs), E (methyl bromide) and F (HFCs).

Global efforts to protect the climate and ozone layer received a boost with the ratification and coming into force of the Kigali Amendment. This is the next step in our battle to secure planet earth. Hydrofluorocarbons which have been used as replacements for many ozonedepleting substances threaten to derail the gains of the Montreal Protocol. These gases will be now phased down under the Kigali Amendment.

\section{CONCLUSION}

The United States, China and India are in separate groups of countries, with different time schedules to phase out their HFCs and replace them with climate-friendly alternatives. India has to reduce its HFC use by $80 \%$ by the year 2047, while China and the United States have to achieve the same target by the year 2045 and 2034 respectively. India will complete its phase down of HFCs in four steps from 2032 onwards with a cumulative reduction of $10 \%$ in $2032,20 \%$ in $2037,30 \%$ in 2042 and $80 \%$ in 2047. This important instrument is crucial to achieving the target of restraining the increase in global temperatures to 2 degree Celsius from pre-industrial times. As pointed out by a recent report of the Intergovernmental Panel on Climate Change (IPCC), the average temperature of the planet has already risen by about 1.1 degree Celsius. The collective action is expected to prevent emissions of upto $\mathbf{1 0 5}$ million tonnes of carbon dioxide equivalent of greenhouse gases helping to avoid up to 0.5 degree Celsius of global temperature rise by 2100 , while continuing to protect the ozone layer. Because HFCs were not ozonedepleting, they were not controlled substances under the Montreal Protocol. They were part of the problematic greenhouse gases whose emissions are sought to be curtailed through climate change instruments such as the Kyoto Protocol of 1997 and the 2015 Paris Agreement.

\section{REFERENCES}

1. DR Khullar and JACS Rao, EnvironmentMcGraw Hill Education (India) Private Limited, New Delhi, 2016

2. Main Greenhouse Gases, Centre for Climate and Energy Solutions (C2ES) https://www.c2es.org/content/main-greenhouse-gases/

3. Dr. Pieter Tans, NOAA/ESRL https://gml.noaa.gov/ccgg/trends/ and Dr. Ralph Keeling, Scripps Institution of Oceanography, https:// scripps co2. ucsd.edu/

4. NOAA, 2020, United States Environmental Protection A ge n c y (EPA) https://www.epa.gov/climate-indicators/climate-change-indicatorsclimate-forcing

5. https://en.wikipedia.org/wiki/United Nations Framework Convention onClimate Change

6. United Nations Climate Change (UNFCCC) its annual report 2020, available 
at https://unfccc.int/sites/default/files/resource/ UNFCCC_Annual Report 2020.pdf

7. United National Climate Change (UNFCCC) on Kyoto protocol, 2012, https://unfccc.int/kyoto_protocol

8. UNFCCC on Kyoto Protocol Reference Manual on Accounting of Emissions and Assigned Amount, available at https://unfccc.int/sites/default/files/ 08 unfccc kp ref manual.pdf

9. UNFCCC on Paris Agreement- https://unfccc.int/process-and-meetings/ the-paris-agreement/the-paris-agreement

10. Adopted on 15 September 1987 , the Protocol, UN treaty ratified every country on Earth - all 198 UN Member State

11. United Nations on Environment Protection (UNEP) on https://www.unep.org/ ozonaction/who-we-are/about-montreal-protocol

12. Article 3 the Montreal Protocol on Substances that Deplete the Ozone Layer 1987

13. Article 4 the Montreal Protocol on Substances that Deplete the Ozone Layer, 1987

14. Article 5 the Montreal Protocol on Substances that Deplete the Ozone Layer, 1987

15. Article 7 the Montreal Protocol on Substances that Deplete the Ozone Layer, 1987

16. Article 8 the Montreal Protocol on Substances that Deplete the Ozone Layer, 1987

17. Article 10 the Montreal Protocol on Substances that Deplete the Ozone Layer, 1987

18. The Kigali Amendment to the Montreal Protocol is an international agreement to gradually reduce the consumption and production of hydrofluorocarbons. It is a legally binding agreement designed to create hydrofluorocarbons. It is a legally binding agreement designed to create
rights and obligations in international law, Indian Cabinet approves ratification of Kigali Amendment to the Montreal Protocol on Substances that Deplete the Ozone Layer of phase down of Hydrofluorocarbons its National strategy for phase down Hydrofluorocarbons after required consultation with all the industry stakeholders by 2023 